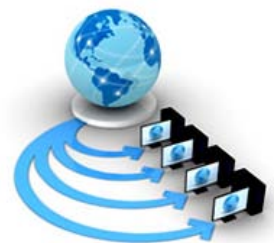

International Journal of Advanced Research in Computer Science

RESEARCH PAPER

\title{
EXTACTION \& STEGNOGRAPHY OF IRIS DATA INTO HAND VEIN IMAGES WITH AUDIO CONVERSION CRYPTOGRAPHY FOR ENHANCING BIOMETRIC SECURITY
}

\author{
Khusboo Joshi \\ M. Tech Scholar \\ (Digital Communication) \\ Global Institute of Technology, Jaipur
}

\author{
Gajanand Gupta \\ Assistant Professor \\ (Communication \& Signal Processing) \\ Global Institute of Technology, Jaipur
}

\begin{abstract}
Biometric acknowledgment is a standout amongst the most trusted and secures technique for individual acknowledgment and verification. As the biometric framework validation requires biometric format information of an individual novel element, for example, unique mark iris programming, hand structure, confront and so forth. To be put away in information base for coordinating, for a man's protection and is utilizes as a layout information. In this work, we use stenography information coordinating procedure alongside organize transformation to improve bio metric layout solid, transmission and validation security. As hand vein design and iris design does not change with maturing, the some have been taken to spare imperative attributes, for example, exuberance, permanency unwavering quality and so forth. Our proposed conspire actualizes a one of a kind of biometric security by extaction the iris format from iris picture, installing the iris layout in to hand vein pictures, and the finding changing over inserted hand vein picture into a sound flag, which will be heard as commotion to an arbitrary audience in this way giving a multitier security cover to format abuses and protection intension.
\end{abstract}

Keywords: Image Stegnography, Image Audio Cryptography, Template Security, Biometric Identification, Iris Hand Vein Authentication, Watermarking, Embedding.

\section{INTRODUCTIONA}

Biometrics suggests estimations related to human properties. Biometrics confirmation (or sensible validation) is used as a piece of programming designing as a kind of recognizing evidence and get the opportunity to control. It is in like manner used to perceive individuals in bundles that are under surveillance. [2]

Biometric identifiers are then unmistakable, quantifiable credits used to name and depict people. Biometric identifiers are often arranged as physiological versus behavioral qualities. Physiological qualities are related to the condition of the body. Outlines consolidate, yet are not compelled to special stamp, palm veins, defy affirmation, DNA, palm print, hand geometry, iris affirmation, retina and notice/fragrance. Behavioral qualities are related to the case of lead of a man, including yet not obliged to composing rhythm, stride, and voice. A few examiners have created the term behaviometrics to delineate the last class of biometrics. [3]

More regular strategies for get the opportunity to control fuse token-based ID systems, for instance, a driver's allow or worldwide ID, and learning based unmistakable evidence structures, for instance, a watchword or individual recognizing confirmation number. Since biometric identifiers are uncommon to individuals, they are more strong in checking identity than token and learning based methods; in any case, the gathering of biometric identifiers raises security stresses over a complete usage of this information. [4]

Second, in unmistakable verification mode the structure plays out a one-to-various examination against a biometric database endeavoring to set up the character of a dark individual. The

system will win with respect to perceiving the individual if the relationship of the biometric test to a design in the database falls inside a some time ago set edge. Recognizing verification mode can be used either for 'valuable affirmation' (with the goal that the customer does not have to give any information about the arrangement to be used) or for 'opposite affirmation' of the person "where the system develops whether the individual is who she (evidently or explicitly) denies to be". The last limit must be proficient through biometrics since various procedures for singular affirmation, for instance, passwords, PINs or keys are inadequate. [5]

The principal gone through an individual uses a biometric structure is called selection. In the midst of the enrollment, biometric information from an individual is gotten and secured. In following uses, biometric information is distinguished and differentiated and the information set away at the period of enrollment. Note that it is important that limit and recuperation of such structures themselves be secure if the biometric system is to be solid. The principle square (sensor) is the interface between this present reality and the system; it needs to get all the essential data. By far most of the conditions it is a photo securing structure, in any case it can change as demonstrated by the characteristics fancied. The second piece plays out all the fundamental pre-dealing with: it needs to remove old rarities from the sensor, to enhance the data (e.g. emptying establishment bustle), to use some kind of institutionalization, et cetera. In the third square indispensable components are isolated. This movement is a basic walk as the correct components ought to be isolated in the perfect way. A vector of numbers or a photo with particular properties is used to make a format. An organization is a blend of the germane characteristics isolated from the source. Segments of the biometric estimation that are not used as a piece of the examination computation are discarded in the format to diminish the record measure and to guarantee the identity of the enrollee.[7] 


\section{LITERATURE REVIEW}

N. Lalithamani depicted that; Biometric acknowledgment is imperative strategy for acknowledgment of individual as of late. Here, a typical concern is biometric security which is the protection issues got from capacity and abuses of the format information. So as to deal with this issue, examines have proposed distinctive calculations to be gone up against by security of biometric frameworks. Two noteworthy ways are, In this paper, we use a watermarking innovation to enhance the layout security in biometric confirmation. As per, two modalities, for example, iris and hand vein is taken to save the qualities of energy and permanency. Our proposed strategy for implanting of iris information to hand vein pictures utilizing watermarking innovation to enhance format security in biometric acknowledgment is done in light of the accompanying strides.

In the acknowledgment stage, iris design is separated from the implanted picture and afterward, coordinating is finished with inquiry pictures. A ultimate conclusion of validation is done in view of the item administer based score level combination. The usage is finished utilizing MATLAB and the execution of the strategy is examined with FAR, FRR and exactness. Antagonistic impacts of fear mongering have expanded use of validating people. These days, eyes have swung to utilize biometric ideas to meet the prerequisite. Biometric framework, which is an example acknowledgment framework, abuses a client's incomparable physical characteristics to recognize/verify him/her Two noteworthy gatherings of undertakings that contribute in a biometric framework are distinguishing proof and verification Biometric methods considers various qualities, for example, facial thermo gram, hand vein, stride, keystroke, scent, ear, unique finger impression, confront, hand geometry, retina, palm print, iris, voice and mark Biometrics shows as a potential device when consolidated with conventional confirmation plots that extraordinarily bolster in building up realness . [1]

\section{PROPOSED WORK}

1. Improvement of a propelled procedure for installing biometric pictures in other biometric pictures to make a half breed impressive recognizable proof instrument.

2. A reasonable blend can be of implanting Iris/Retina information in Hand Vein Images to enhance recognizable proof exactness. Another appropriate mix can be installing of Fingerprint Data in Face Image Data.

3. Conceivable utilization of cutting edge vector Stegnography and recurrence area watermarking to install different biometric and non-biometric watermarks in principle biometric picture.

4. Our proposed stage takes into account utilization of different recognizable proof and get to/exchange control frameworks to work in synchronization, for example, RFID/Magnetic Cards.

5. The proposed framework might be upgraded to give biometric confirmation administrations utilizing on the web servers for serving E-Commerce and E-Governance Platforms.
6. Interesting Machine ID of Biometric Scanner can be implanted in the biometric pictures alongside watermark biometric pictures to follow backer credibility.

7. Utilization of cutting edge cryptography strategies alongside the Stegnography methods to pre-cryptograph the biometric/non-biometric pictures before installing into Main biometric picture in order to additionally reinforce the security of the proposed framework.

\section{METHODOLOGY}

\section{IRIS affirmation}

Iris affirmation is an automated methodology for biometric ID that usages logical case affirmation frameworks on video pictures of both of the irises of a man's eyes, whose bewildering illustrations are exceptional, stable, and can be seen from some detachment.

A couple of hundred million individuals in a couple of countries around the world have been enrolled in iris affirmation systems for settlement purposes, for instance, global ID free motorized periphery convergences and some national ID programs. A key ideal position of iris affirmation, other than its speed of planning and its over the top impenetrability to false matches, is the security of the iris as an inward and guaranteed, yet remotely detectable organ of the eye. [6] [8]

\section{Hand vein affirmation}

Hand Vein organizing, also called vascular innovation, is a strategy of biometric recognizing verification through the examination of the cases of veins clear from the surface of the skin. Despite the fact that used by the Federal Bureau of Investigation and the Central Intelligence Agency, this procedure for ID is as yet being created and has not yet been all around got by wrongdoing labs as it is not considered as strong as more settled frameworks, for instance, fingerprinting. Regardless, it can be used as a piece of conjunction with existing criminological data in help of a conclusion. While distinctive sorts of biometric scanners are more common for security systems, Vascular scanners are creating in popularity. One of a kind finger impression scanners are more occasionally used; however Naito says they generally don't give enough data centers to fundamental affirmation decisions. Since one of a kind check scanners require facilitate contact of the finger with the scanner, dry or rubbed skin can intrude with the faithful nature of the system. Skin contaminations, for instance, psoriasis can in like manner oblige the accuracy of the scanner; likewise organize contact with the scanner can achieve necessity for more progressive cleaning and higher risk of equipment hurt. [9]

\section{System block diagram}

Transmission block diagram 


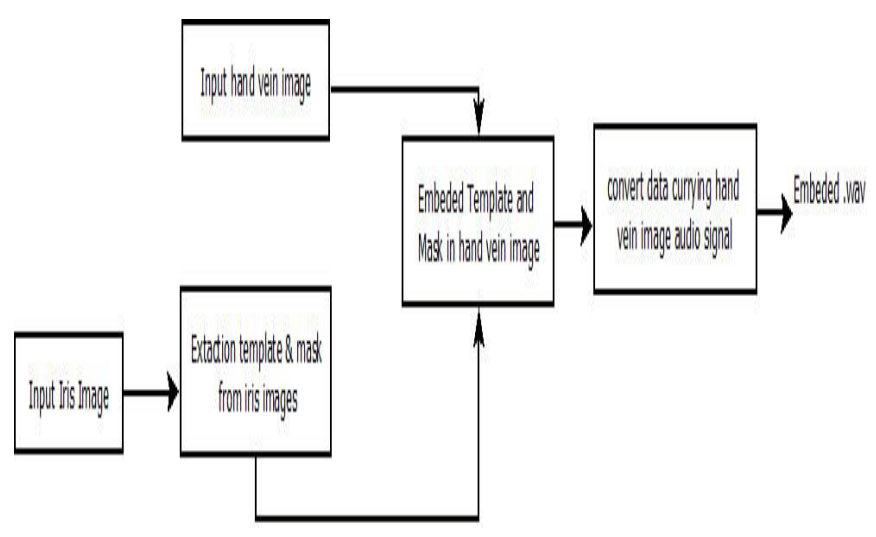

Reception block diagram

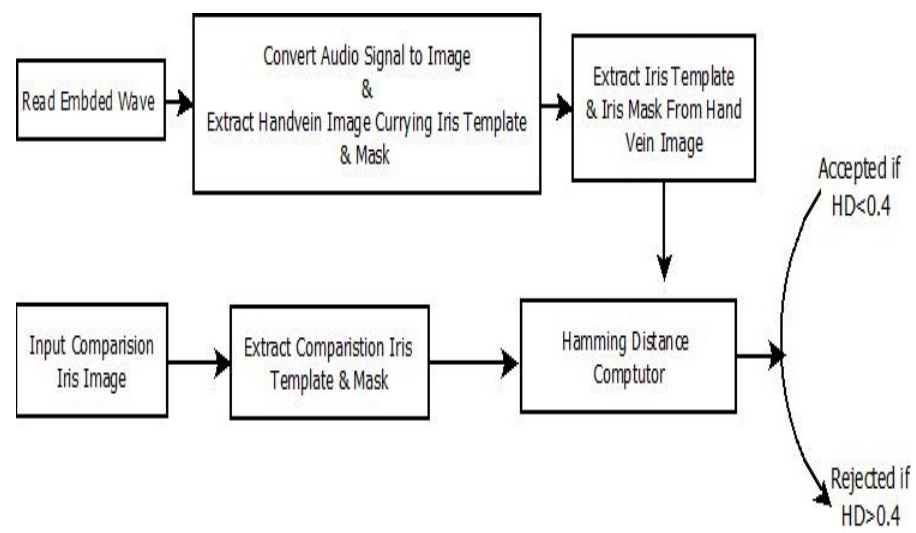

Computing time for matching between iris images, if time wills less than 0.4 then template will be accepted and if time is greater than 0.4 then iris comparison will be rejected. And value of hand vein image and space accomplice in hand vein image, and wave file and wave file bit rate table is given is below.

\section{RESULT}

Screen shot 1

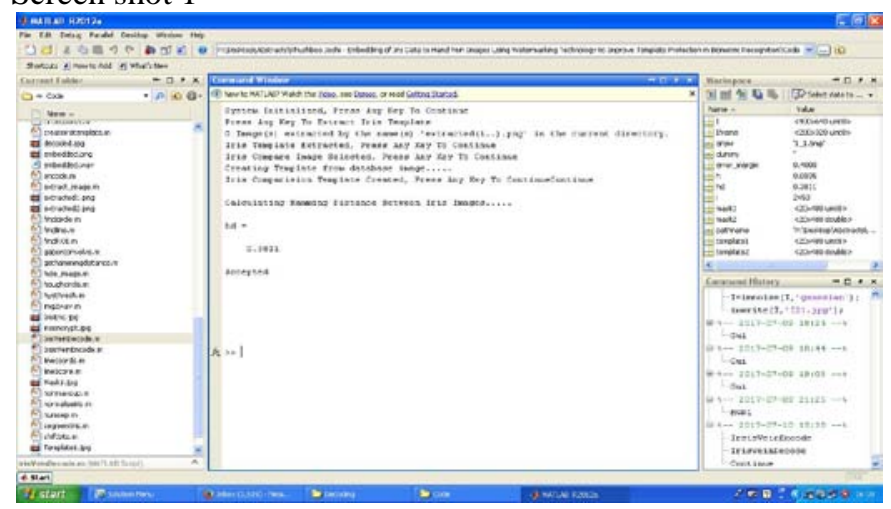

Fig1.1 Computing Time

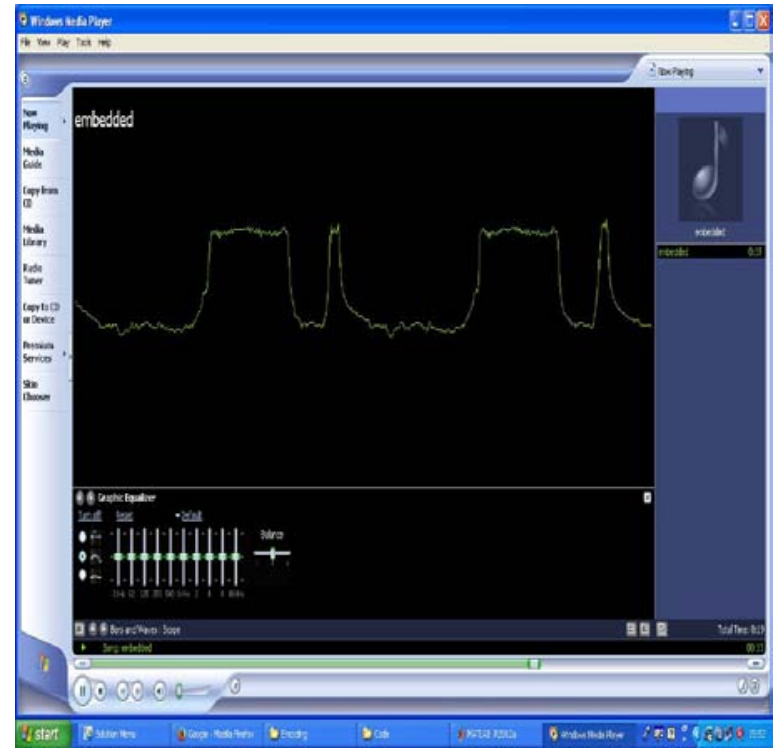

Fig 1.2 Audio Wave

Table 1.1 Hand Vein Image and Iris Image and Space Accomplice in Hand Vein Image, Wave File Size and Wave File Bit Rate

\begin{tabular}{|c|c|c|c|c|c|}
\hline S. No & $\begin{array}{c}\text { Hand Vein } \\
\text { Image }\end{array}$ & Iris Image & $\begin{array}{c}\text { Space } \\
\text { Accomplice In } \\
\text { Hand Vein } \\
\text { Image }\end{array}$ & Wave File Size & $\begin{array}{c}\text { Wave File Bit } \\
\text { Rate }\end{array}$ \\
\hline 1. & $\mathrm{~L}-01$ & $1-0$ & $50.0234 \%$ & $600 \mathrm{kbps}$ & $256 \mathrm{kbps}$ \\
2. & $\mathrm{~L}-02$ & $1-0$ & $50.0234 \%$ & $600 \mathrm{kbps}$ & $25 \mathrm{kbpps}$ \\
3. & $\mathrm{R}-01$ & $1-0$ & $50.0234 \%$ & $600 \mathrm{kbps}$ & $256 \mathrm{kbps}$ \\
4. & $\mathrm{R}-02$ & $1-0$ & $50.0234 \%$ & $600 \mathrm{kbps}$ & $256 \mathrm{kbps}$ \\
\hline 5. & $\mathrm{~L}-01$ & $1-1$ & $50.0234 \%$ & $600 \mathrm{kbps}$ & $256 \mathrm{kbps}$ \\
6. & $\mathrm{~L}-02$ & $1-1$ & $50.0234 \%$ & $600 \mathrm{kbps}$ & $256 \mathrm{kbps}$ \\
7. & $\mathrm{R}-01$ & $1-1$ & $50.0234 \%$ & $600 \mathrm{kbps}$ & $256 \mathrm{kbps}$ \\
8. & $\mathrm{R}-02$ & $1-1$ & $50.0234 \%$ & $600 \mathrm{kbps}$ & $256 \mathrm{kbps}$ \\
\hline 9. & $\mathrm{~L}-01$ & $2-0$ & $50.0234 \%$ & $600 \mathrm{kbps}$ & $256 \mathrm{kbps}$ \\
10. & $\mathrm{~L}-02$ & $2-0$ & $50.0234 \%$ & $600 \mathrm{kbps}$ & $256 \mathrm{kbps}$ \\
11. & $\mathrm{R}-01$ & $2-0$ & $50.0234 \%$ & $600 \mathrm{kbps}$ & $256 \mathrm{kbps}$ \\
12. & $\mathrm{R}-02$ & $2-0$ & $50.0234 \%$ & $600 \mathrm{kbps}$ & $256 \mathrm{kbps}$ \\
\hline 13. & $\mathrm{~L}-01$ & $2-1$ & $50.0234 \%$ & $600 \mathrm{kbps}$ & $256 \mathrm{kbps}$ \\
14. & $\mathrm{~L}-02$ & $2-1$ & $50.0234 \%$ & $600 \mathrm{kbps}$ & $256 \mathrm{kbps}$ \\
15. & $\mathrm{R}-01$ & $2-1$ & $50.0234 \%$ & $600 \mathrm{kbps}$ & $256 \mathrm{kbps}$ \\
16. & $\mathrm{R}-02$ & $2-1$ & $50.0234 \%$ & $600 \mathrm{kbps}$ & $256 \mathrm{kbps}$ \\
\hline 17. & $\mathrm{~L}-01$ & $3-0$ & $50.0234 \%$ & $600 \mathrm{kbps}$ & $256 \mathrm{kbps}$ \\
18. & $\mathrm{~L}-02$ & $3-0$ & $50.0234 \%$ & $600 \mathrm{kbps}$ & $256 \mathrm{kbps}$ \\
19. & $\mathrm{R}-01$ & $3-0$ & $50.0234 \%$ & $600 \mathrm{kbps}$ & $256 \mathrm{kbps}$ \\
20. & $\mathrm{R}-02$ & $3-0$ & $50.0234 \%$ & $600 \mathrm{kbps}$ & $256 \mathrm{kbps}$ \\
\hline 21. & $\mathrm{~L}-01$ & $3-1$ & $50.0234 \%$ & $600 \mathrm{kbps}$ & $256 \mathrm{kbps}$ \\
22. & $\mathrm{~L}-02$ & $3-1$ & $50.0234 \%$ & $600 \mathrm{kbps}$ & $256 \mathrm{kbps}$ \\
23. & $\mathrm{R}-01$ & $3-1$ & $50.0234 \%$ & $600 \mathrm{kbps}$ & $256 \mathrm{kbps}$ \\
24. & $\mathrm{R}-02$ & $3-1$ & $50.0234 \%$ & $600 \mathrm{kbps}$ & $256 \mathrm{kbps}$ \\
\hline
\end{tabular}

\section{CONCLUSION}

In this work, we have presented a unique \& efficient biometric authentication system with a high degree of template security using two modalities of iris (retina scan) we have used steganography or water matching to improve the security \& reliabilities of the existing system. Also a unique method of enhancing security by converting an image into an audio signal is employed so as to decoy the unintended receiver will only intercept noise in the audio domain \& thus we have been able to provide for a two tier security based biometric authentication system that demphonstate a high degree of reliability \& flexibilities its operation which enhancing the privacy of the user \& template misuse protection manifolds. Also the template matching system where recovered iris template from hand vein image are compared to iris template data using euclinder distance. Iris system also provides for variation of detection threshold to modify track off detection accuracy \& rejection entries.

Result value. 


\section{FUTURE SCOPE}

As per the above, the above proposed method; implements a highly versatile \& secure biometric authentication system; a lot of improvements are proposed in future that can further enhance the system capabilities. The accuracy of the existing system can further enhanced by using high resolution capture devices. Also by employing artificial intelligence authentication accuracy many folds. As the final embedded image is converted to an audio signal, for decaying the union tended receivers, by can be decoded by suitable algorithm, the some can be improved by usage of public private key cryptography. [10]

\section{REFERENCE}

[1] Embedding of iris data to hand vein images using watermarking technology to improve template protection in biometric recognition $\mathrm{n}$. Lalithamani department of computer science and engineering amrita school of engineering amrita vishwa vidyapeeth amritanagar (po) ettimadai, coimbatore

[2] Templates fusion with roi using watermarking technology international journal of engineering sciences \& research technology k. vamsi*, dr. raman chadha, salony tuli * pg scholar, department of cse, chandigarh group of college technical campus, jhanjeri, mohali, india professor and head, department of cse, chandigarh group of college technical campus, jhanjeri, mohali, india asst.professor department of cse, chandigarh group of college technical campus, jhanjeri, mohali, india

[3] Embedding iris image watermark in hand vein image to improve biometric security www.ijraset.com volume 5 issue v, may 2017 ic value: 45.98 issn: 2321-9653 international journal for research in applied science \& engineering technology (ijraset) Cijraset: all rights are reserved $1486 \mathrm{mr}$. pavan malghan, mrs s. s. vasekar2 1pg student, signal processing, skncoe, vadgaon (bk), pune, india assistant professor, vlsi and embedded system, skncoe, vadgaon (bk), pune, india
[4] Multimodal biometric template authentication of fingervein and signature using visual cryptography International journal of engineering and techniques volume 3 issue 3, may-june 2017 issn: 2395-1303 http://www.ijetjournal.org page shaik riyaz ulhaq , shaik imtiyaz, selva kumar, gopinath 1,2viii semester ,ece department,srm university, chennai 3sr.assistant professor, ece department,srm university, Chennai

[5] Embedding of iris to hand vein images based on watermarking technology for biometric recognition k.s.chamini pg scholar, department of ece, sri venkatesa perumal college of engineering and technology, puttur. c. manikanta, m.tech assistant professor, department of ece, sri venkatesa perumal college of engineering and technology, puttur.

[6] "A study on biometric template protection techniques," p. poongodi, and p. betty, international journal of engineering trends and technology (ijett), vol. 7, no. 4, 2014.

[7] "Biometric template security using invisible watermarking with minimum degradation in quality of template, r. yadav, kamaldeep, r. saini, and r. nandal, international journal on computer science and engineering, vol. 3, no. 12, 20 i i.

[8] Watermarking of iris data in hand vein images for protection in biometric recognition saniaasma, b. raghunath reddy pg scholar, dept of ece(decs), dr.k.v.subba reddy college of engineering for women, kurnool, ap, india, e-mail: sania.asma93@gmail.com. 2asst prof, dept of ece, dr.k.v.subba reddy college of engineering for women, kurnool, ap, india, email: bynagari.raghu@gmail.com.

[9] "Embedding of iris data to hand vein images using watermarking technology to improve template protection in biometric recognition”, n. lalithamani, dr.m. sabrigiriraj, ieee 2015.

[10]A novel retina based biometric privacy using visual cryptography ijcsns international journal of computer science and network security, vol.16 no.9, september 2016 manuscript received september 5, 2016 manuscript revised september 20, $2016 \mathrm{~m}$. suganya1 and k. krishnakumari research scholar, department of computer science, rathnavel subramaniam college of arts \& science, sulur, india. 2director, department of mca, rathnavel subramaniam college of arts \& science, sulur, india 